\title{
Utilizing Zoom Breakout Rooms to Expose Preclerkship Medical Students to TeleMedicine Encounters
}

\author{
Jessica Rucker ${ }^{1}$ (D) Susan Steele ${ }^{1} \cdot$ Justin Zumwalt ${ }^{1} \cdot$ Natasha Bray $^{1}$ \\ Accepted: 6 October 2020 / Published online: 14 October 2020 \\ (C) International Association of Medical Science Educators 2020
}

\begin{abstract}
Emergency Remote Teaching (ERT) presented various challenges as the Oklahoma State University Center for Health Sciences (OSU-CHS) campus closed to students in response to COVID-19 mitigation efforts in late March 2020. While some classes transitioned easily to virtual platforms already in place, such as learning management systems and the lecture recording software, other classes that involved coordinated group activities did not have as many suitable alternatives. One College of Osteopathic Medicine (COM) class utilized the teleconferencing tool Zoom. Zoom's breakout rooms and waiting room features were used to facilitate a clinical interviewing skills lab and telemedicine-type encounter with standardized patients. We were able to successfully designate groups of approximately 10 students into three rooms, amongst which the standardized patients moved at set intervals. Faculty facilitators participated in each room to guide students, and one support staff member served as host to manage the technical aspects of the overall meeting. We found this approach to be a successful alternative to live group activities and a worthwhile opportunity to expose preclerkship students to telemedicine.
\end{abstract}

Keywords Emergency remote teaching $\cdot$ Online learning $\cdot$ Distance learning $\cdot$ Telemedicine $\cdot$ Preclerkship

The COVID-19 pandemic disrupted the planned curriculum delivery for schools everywhere in early 2020. For Oklahoma State University Center for Health Sciences (OSU-CHS), while many classes transitioned fairly smoothly to Emergency Remote Teaching (ERT), classes that involved group activities and labs presented more difficult challenges [1].

One class in the College of Osteopathic Medicine (COM) titled Clinical Care Foundations I (CCF I) involved a combination of lectures and group experiences. Some of these experiences involved multiple live "labs" in simulated patient rooms where students learn how to perform a skill (often related to physical examinations and/or patient interviewing) and then have the opportunity to practice it, obtaining live feedback from faculty facilitators. Periodically throughout

Electronic supplementary material The online version of this article (https://doi.org/10.1007/s40670-020-01113-w) contains supplementary material, which is available to authorized users.

Jessica Rucker

jessica.rucker@okstate.edu

1 Oklahoma State University, Center for Health Sciences, Tulsa, OK, USA the semester, students are evaluated on these skills in standardized patient (SP) encounters, where students take on the role of a doctor in simulated patient rooms with an actor as the patient. These encounters give students opportunities to practice preclerkship clinical reasoning skills as doctors in a safe environment.

Once the OSU-CHS campus closed, the course director contemplated strategies to host an upcoming "difficult patient" interviewing skills lab virtually. Along with other faculty, support staff, and the dean of curriculum, the course director considered using the breakout rooms function in Zoom. A test of concept experiment was conducted with the course's instructional design coordinator serving as the "Host," the course director and faculty facilitators as learners, and staff members as standardized patients. Learners were assigned to a respective "breakout room" in which they remained during their series of patient encounters. The standardized patients were designated as "Co-Hosts" for the event so they could move between breakout rooms at a set interval.

Before the lab, a facilitator guide was provided to faculty facilitators to outline the session structure and suggest feedback strategies while a student checklist was provided to students listing the skills they were to demonstrate during the encounter when playing the physician role. Time and staff 
constraints prevented every student from having an opportunity to play the physician role for this particular session.

In order to accommodate 114 first-year students with limited facilitators and standardized patients, we designed three different standardized patient encounters and utilized three Zoom breakout rooms. The class was randomly divided into four different sessions of approximately 28-30 students and 8-10 students were assigned to one of the three breakout rooms during each session. During the encounter, a facilitator selected one student to interview the standardized patient in a 10-min time frame. The other students in the group muted their audio and video and simply observed. This was followed by $8-10 \mathrm{~min}$ of reflection and debriefing. Each session consisted of three encounters and lasted approximately $1 \mathrm{~h}$. To make the transition between sessions smoother (so students in the next session would not join the meeting until the previous group had finished), we enabled the waiting room function and only admitted students when it was time for them to begin.

In this study, we sought to answer the inquiry question, "Do Zoom breakout rooms serve as an effective substitute for live standardized patient encounters, resulting in similar learning outcomes?" by collecting data on student survey feedback and facilitator feedback. We engaged in Participatory Enquiry using Action Research as a result of the shift in curricular delivery and the desire to help students achieve the same learning outcomes in a different way [2]. An application was submitted to the OSU-CHS Institutional Review Board (IRB) and was determined to meet exempted criteria.

A survey sent out for students to gauge the effectiveness of the experience compared to traditional delivery had positive results; debriefing the experience with staff and faculty facilitators immediately after the event over Zoom was also encouraging, though some power bias may exist in viewing the data more favorably and assuming that students would be ready and willing participants. There were no implications on grade/standing since survey results were anonymous.

Because patient interviewing is a key component of telemedicine encounters, this was an excellent opportunity for students to practice effective communication skills in a similar format of healthcare delivery. Major et al. noted similarly encouraging feedback after using Zoom for a Web-OSCE [3]. We plan to utilize breakout rooms in Zoom for other group sessions or telemedicine-type encounters in the future, exploring how the long-term data of performance in standardized patient encounters may reinforce or diminish our conclusion.

Acknowledgments The authors would like to thank all students, faculty, and front-line healthcare workers during this pandemic.

\section{Compliance with Ethical Standards}

Conflict of Interest The authors declare that they have no conflict of interest.

Ethics Approval Not applicable.

Consent to Participate Not applicable.

Consent for Publication Not applicable

\section{References}

1. Hodges M, Moore S, Lockee B, Trust T, Bond A. The difference between emergency remote teaching and online learning. In: Educause Review. https://er.educause.edu/articles/2020/3/thedifference-between-emergency-remote-teaching-and-onlinelearning Accessed 24 Apr 2020.

2. Briggs ARJ, Coleman M, Morrison M. Research methods in educational leadership \& management: 3rd ed. SAGE: Los Angeles; 2012.

3. Major S, Sawan L, Vognsen J, \& Jabre M. COVID-19 pandemic prompts the development of a Web-OSCE using Zoom teleconferencing to resume medical students' clinical skills training at Weill Cornell Medicine-Qatar. In: BMJ Simulation \& Technology Enhanced Learning 2020. https://doi.org/10.1136/bmjstel-2020000629 Accessed 26 Aug 2020.

Publisher's Note Springer Nature remains neutral with regard to jurisdictional claims in published maps and institutional affiliations. 